\title{
Assessment of Public Health Units' Capacity to Manage Under-Five Malnutrition: A Case Study of Kamuli District, Uganda
}

\author{
Benon Musasizi ${ }^{1}$, Elizabeth Ekirapa Kiracho ${ }^{2}$, Saul Kamukama ${ }^{2}$ \& Geoffrey Babughirana ${ }^{1}$ \\ ${ }^{1}$ World Vision international, Kampala, Uganda \\ ${ }^{2}$ College of Health Sciences, School of Public Health, Makerere University, Kampala, Uganda \\ Correspondence: Benon Musasizi, World Vision International, Kampala, Uganda. Email: \\ musasizi.benon1@gmail.com. \\ Received: August 7, 2018 \\ Accepted: November 12, 2018 \\ Online Published: November X, 2018 \\ doi:10.20849/ijsn.v3i3.511 \\ URL: https://doi.org/10.20849/ijsn.v3i3.511
}

\begin{abstract}
Malnutrition is a major public-health problem throughout the developing world and is an underlying factor in over 50\% of the 10-11 million children under 5 years of age who die each year of preventable causes. Uganda loses US\$310 million worth of productivity per year due to the high levels of stunting, iodine-deficiency disorders, iron deficiency, low birth weight, and malnutrition contributes to a loss of about $4.1 \%$ of the gross domestic product per year. This paper provides the findings of an assessment conducted in Kamuli district to determine the capacity of public health units to manage under-five malnutrition focusing on the six building blocks of the health system. This was a descriptive cross sectional study that employed both qualitative and quantitative methods of data collection, analysis and presentation. This involved interviewing health workers using a semi structured questionnaire and checklist for health facilities. Supplement qualitative data was collected using key informant interviews (KIIs). Results indicate that the capacity of health facilities to manage under-five malnutrition in Kamuli district was found to be low at $36.6 \%$ only. Capacity of health facilities was based on; Nutrition leadership and human resource development, health worker knowledge, availability of equipment and supplies, physical infrastructure, availability of infant and young child nutrition policy guidelines and planning and budgeting at health facility level.
\end{abstract}

Keywords: health units' capacity, public health worker, public health units, under nutrition, nutrition care

\section{Introduction}

Maternal and child nutrition is a key driver for sustainable development, yet about155 million children worldwide are still stunted (World Bank 2018). According to UDHS 2016, 29\% of children under 5 are stunted while $11 \%$ of all children are underweight. Half of children age 6-59 months (53\%) suffered from some degree of anaemia: $24 \%$ were classified as mildly anaemic, $27 \%$ as moderately anaemic, and $2 \%$ as severely anaemic. Additionally $66 \%$ of infants under age 6 months are exclusively breastfed.

Every year, undernutrition contributes to the deaths of around 3 million children and threatens the futures of hundreds of millions more undermining the healthy development of their bodies and brains, and affecting their ability to learn and to earn later as adults (Global nutrition report 2016). Malnutrition is a major public-health problem throughout the developing world and is an underlying factor in over 50\% of the 10-11 million children under 5 who die each year of preventable causes (Kate Sadler et al, 2011). According to the Uganda nutrition action plan 2011-2016, Uganda loses US\$310 million worth of productivity per year due to the high levels of stunting, iodine-deficiency disorders, iron deficiency, and low birth weight, and malnutrition contributes to a loss of about $4.1 \%$ of the gross domestic product. Malnutrition is expensive to treat. For instance, treating severe acute malnutrition costs more than US $\$ 120$ per child.

Malnutrition makes the population vulnerable to infections and other diseases and contributes to $60 \%$ of under-five deaths. Sub-optimal child care and inappropriate feeding practices, impact on the health and nutrition of children (Beatrice Olack et al 2011). The persistence of high case-fatality rates in health facilities is commonly attributed to inappropriate case management as a result of poor knowledge. The accepted view is that wider implementation of the WHO (2010) guidelines through in-service training and its incorporation into medical and nursing curricula is the key to substantially decreasing case-fatality rates worldwide. Studies suggest 
that the availability of sufficient resources, particularly skilled and motivated health staff, is a vital determinant of success and effectiveness for management of malnutrition (Steve Collins 2007).

According to the Ministry of Health (MoH) 2010/11-2014/15: Health sector Strategic plan (HSSP), health services in the district are mainly provided by government health facilities that include a hospital and a number of health centres (2 HC IV, $10 \mathrm{HC}$ III and $22 \mathrm{HC}$ II units). A number of non-state actors also play a role in provision of health services in the district as attested to by the existence of an NGO hospital and a number of private health facilities. Kamuli district has 2 Hospitals - 1 Government hospital and 1 NGO hospital, 2 health centre IV and 10 health centre IIIs (all government) and 34 health centre IIs (22 government, 10 NGO and 2 private). The community level has Village Health Teams (VHT) for reaching the communities. Community participation and empowerment is the strategy for enabling communities to take responsibility for their own health and well-being and to participate actively in the management of their local health services. Although Kamuli district has a fair distribution of health facilities, most of them are located in either Buzaya county or Bugabula county and the 2 hospitals are situated in Kamuli Town.

In response to a high burden of malnutrition, the MoH developed an integrated strategy for management of malnutrition in Uganda where public health units have a vital function (IMAM, 2010). However, it was not known whether public health units have adequate capacity in terms of nutrition leadership/governance, nutrition workforce (numbers and skills), availability and access to equipment and essential nutrition medicines and nutrition financing for public health facilities to adequately manage under-five malnutrition.

This paper provides the findings of an assessment conducted in Kamuli district to determine the capacity of public health units to manage under-five malnutrition focusing on the six building blocks of the health system.

\section{Methodology}

\subsection{Study Area}

The study was conducted in Kamuli District which is part of the former Busoga District (Luwero region). The district borders River Nile and Kayunga district in the west, Jinja district in the South, Iganga district in the Southeast, Kaliro District in the East and Soroti district and Lake Kyoga in the north. Kamuli district population is estimated at 554,100 with a population growth rate estimated at 5.1\% per year. Administratively, Kamuli District is composed of three counties namely: Budiope, Bugabula and Buzaaya. The District is also composed of 17 lower local councils (Sub-counties) and one Town council, and 1,284 villages. The district is composed of three health sub-districts of Bugabula south, Bugabula north and Buzaaya.

\subsection{Study Design}

This was a descriptive cross sectional study that employed both qualitative and quantitative methods of data collection, analysis and presentation. This involved interviewing health workers using a semi structured questionnaire and checklist for health facilities. Supplement qualitative data was collected using key informant interviews (KIIs).

\subsection{Data Collection and Analysis}

Quantitative data was collected using checklists and semi-structured questionnaires. Qualitative data including information on advocacy for under-five nutrition interventions, funding for nutrition activities, nutrition coordination, and bottlenecks/recommendations to management of under-five malnutrition were generated from key informants. The data analysis followed the objectives and research questions. Quantitative data was analyzed using SPSS version 16.0 and presented as frequencies, proportions, and tables. Qualitative data was analyzed using master sheet technique and presented in text form.

\subsection{Ethical Consideration}

Clearance was sought from the school of public health, Makerere University, institutional review board (IRB), Kamuli district local government and selected health units before conducting the study. After clearly explaining the purpose of the study, consenting participants signed consent forms before gathering information from them. Access to data was only limited to persons directly or otherwise related to the study.

\section{Results}

\subsection{Social Demographic Characteristics of the Health Workers}

The age range of health workers was 20 to 60 with mean age of 38.3years and standard deviation (SD) of 10.7. The cadres selected for the study include medical officers, clinical officers, midwives, nurses and lab assistants who constituted $24.1 \%$. 9.6\% had served for less than 2years, $30.2 \%$ had served for 2 to 5 years while $60.2 \%$ had 
served 6 or more years. $21.7 \%$ of the health workers interviewed worked in HC IV and above while $78.3 \%$ were from HC III and II. Majority of the health workers were females (70\%).

\subsection{Public Health Units' Capacity for Management of Under-Five Malnutrition}

The capacity of health facilities to manage under-five malnutrition in Kamuli district was found to be low at $36.6 \%$ only. Capacity of health facilities was based on; Nutrition leadership and human resource development, health worker knowledge, availability of equipment and supplies, physical infrastructure, availability of infant and young child nutrition policy guidelines and planning and budgeting at health facility level.

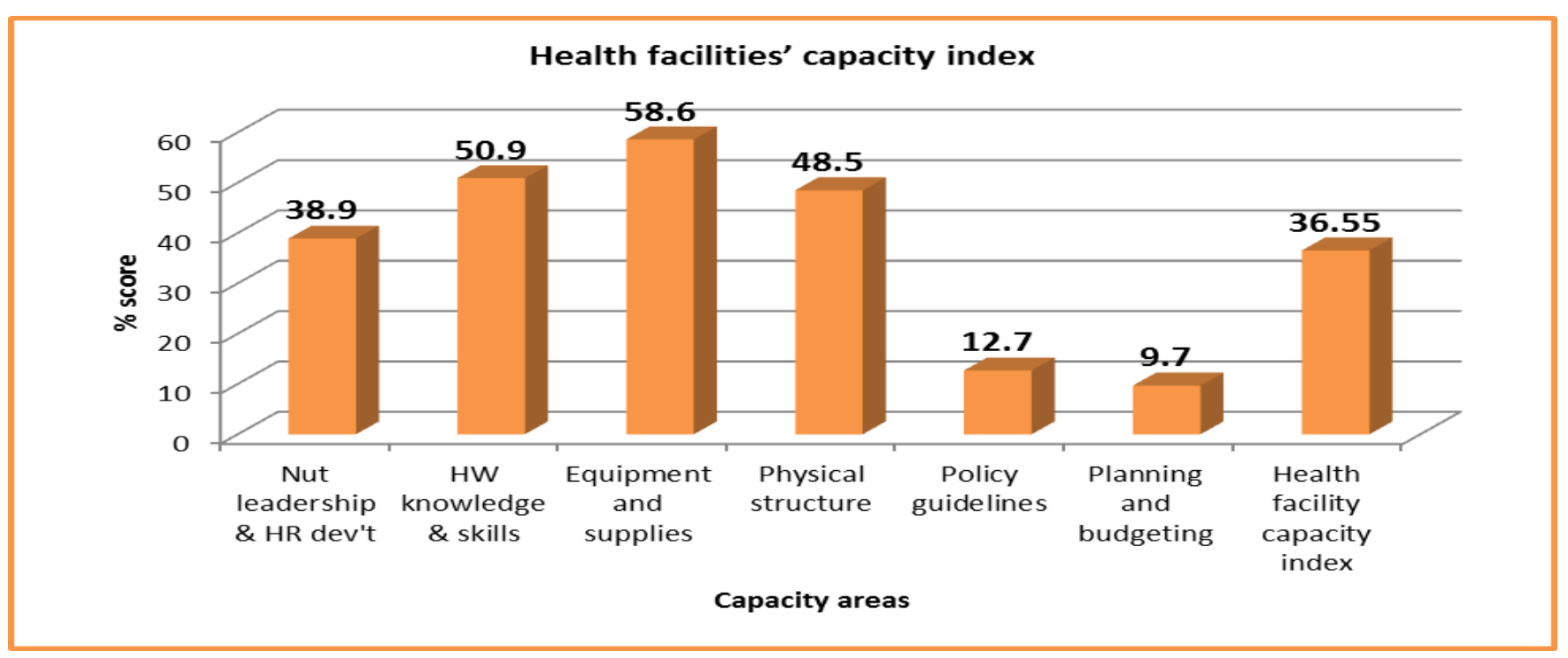

Figure 1. Health facilities capacity index

\section{Discussion}

The aim of this study was to assess the capacity of public health units to manage under-five malnutrition. The study shows that the capacity of public health facilities to manage under five malnutrition in Kamuli district is at $36.6 \%$. These findings imply that public health facilities in Kamuli district are below average in terms of adequate management of under-five malnutrition. Health workers perceive lack of motivation to do nutrition work, limited health workers' nutrition knowledge and skills, and low funding for nutrition activities in health facilities as the most outstanding barriers to adequate management of malnutrition.

Health workers outlined perceived solutions to the barriers as: 1) increasing facilitation for health workers to do nutrition work, 2) provide necessary equipment and supplies to all health facilities, 3) train all health workers responsible for management of malnutrition, 4) strengthen district support supervision for nutrition activities and 5 ) increasing funding for nutrition activities. Here below is a discussion of key findings by objectives of the study.

\subsection{Nutrition Leadership and Human Resource Development}

The study indicates that health facilities nutrition leadership and human resource development capacity is at $38.9 \%$. It is important to note that human resources constitute a critical element of a well-functioning and performing health system. Improvement in the quality of services and achievement of health outcomes depends on available, competent, and motivated workers. This study revealed low staffing levels for positions directly responsible for management of under-five malnutrition in all public health facilities. "The health man power which we have in Kamuli district is around 50\%, so if we have to render quality services to our people, we can't with the current man power. In addition there has been an increase of districts and in some cases health facilities without corresponding increase in human resources for health" one of the health workers observed. The human resources for health audit report (MOH, October 2010) has similar findings; the proportion of approved positions filled by appropriately recruited health workers was $53 \%$ for all the 80 districts with actual vacancy rate of $52 \%$. 
Additionally, the study showed that none of the public health facilities employed a qualified nutritionist in Kamuli district. Similarly, the Uganda nutrition situation analysis (2010) by Fanta project indicated that district/local government staff structure includes one nutritionist at general hospitals but only 10 of 83 districts have nutritionists. Human resource for health (HRH) is the critical limiting factor determining the health of the population besides socioeconomic, behavioural and environmental factors. Globally, there is a close correlation between the concentration of qualified health workers and key health outcomes such as immunization coverage, primary health care outreach, and infant, under-5 and maternal survival. This is because "in health systems, workers function as gatekeepers and navigators for the effective, or wasteful application of all other resources such as drugs, vaccines and supplies", (Syed Masud Ahmed, Md Awlad Hossain et al 2011). Further study findings indicated that only $21 \%$ of the public health units documented human resource needs for nutrition services. Proper human resource development requires documentation of human resource needs to guide human resource planning. According to Human Resource Council for the nonprofit sector (2010), strategic human resource planning is also important from a budgetary point of view so that you can factor the costs of recruitment, and training, into organization's operating budget.

Though supervision is a key component for any project or Programme implementation, the study found out that capacity of health facilities based on supervision is 50.7\%. The HSSP III observes that implementation of MCH interventions is hampered by inadequate supervision. It further indicates that while systems for supervision, monitoring and evaluation exist, there are enormous challenges. Health facility visits by supervisors are irregular due to late release of funds, insufficient funds and inadequate transport arrangements. This compares very well with study findings which indicated limited transport facilities with bicycles as the most common form of transport. Transport is one of the most important requirements needed for the delivery of nutrition services especially during outreaches. The HSSP III acknowledges that transport is often inadequate in public health facilities and is one of the causes of poor supervision and monitoring.

HSSP III also notes that supervisory and monitoring visits have been ineffective due to insufficient feedback to the districts. This compares well with the study findings that indicated $54 \%$ of the health workers who received support supervision did not get feedback. According to NHS (2012), feedback is important for the ongoing development of learners in health care settings. Feedback is central to developing learner's competence and confidence at all stages of their medical careers. Learners value feedback highly and valid feedback is based on observation.

\subsection{Health Worker Knowledge and Skills for Under-Five Nutrition Management}

Based on knowledge and skills, health workers capacity to manage under-five malnutrition was found to be 50.9\%. According to Zultiquar A et al, 2010, to offer specialized care, there is need for a dedicated cadre of competent, knowledgeable and skilled health workers as provider training is directly related to better quality of care. Syed Masud Ahmed 2011, further mentions that to develop an effective, efficient and equitable health system for meeting the goal of improved and equitable population health, human resources for health (HRH) should be appropriate in relation to number, skill-mix, and distribution with optimum competency and motivation.

A systematic review conducted by Bruno F. Sunguya, Krishna C et al 2013 observes that medical and nursing education lack adequate practical nutrition training to fit the clinical reality that health workers face in their practices. Such a deficit creates health workers with poor nutrition knowledge and child undernutrition management practices. In-service nutrition training can help to fill this gap. Review of studies with nutrition counselling as an outcome variable following nutrition training of health workers in Brazil among doctors and pediatricians, a significantly higher proportion of doctors in the intervention group had better post-training counselling skills and performed more nutrition counselling compared to the respective control group. Physicians undergoing the training intervention also showed higher mean communication skill scores compared to untrained physicians. In addition $\mathrm{MoH} 2016$ emphasized that success in management of malnutrition depends on supplies and equipment, but most of all, on dedicated and appropriately trained health workers. Each client requires proper treatment, care, and attention at each phase of care. When this is done, the risk of death can be substantially reduced and the opportunity for full recovery greatly improved.

\subsection{Essential Equipment and Supplies}

The study found out that the capacity of health facilities for essential equipment and supplies is only $58.6 \%$. The HSSP III points to the same direction noting that anthropometric and other equipment for managing and monitoring nutrition programmes are found in very few health facilities. The HSSP III emphasizes procurement of nutrition equipment to support and encourage demonstrations on food preparations at health facility level. 
This is one of the strategies for improving access and quality of nutrition services at community and health facility level.

According to the HSSP III, food and food supplements are the primary medicines used in promotive nutrition, prevention of malnutrition and therapeutic diets used in treatment of the malnourished individuals, however are found in very few health facilities. Strides baseline report for Kamuli district 2010 points to the same situation, the drug shortages as observed at the time of the baseline together with HMIS record of stock outs pose a major challenge to service delivery in Kamuli district. Christopher Potter and Richard Brough 2004, define performance capacity as the tools, money, equipment, consumables, etc. available to do the job. However a doctor, however well trained, without diagnostic instruments, drugs or therapeutic consumables is of very limited use. In terms of therapeutic diets, the study compares very well with Rukundo et al (2010) mentioned that no major hospital provides finances to buy therapeutic milk for treating children with severe acute malnutrition. It is important to note that for adequate management of children with malnutrition, it requires that health facilities are stocked with essential drugs for proper treatment of related medical complications and nutritional deficiencies.

\subsection{Physical Infrastructure}

Regarding infrastructural capacity, the health facilities were found operating at only $48.5 \%$. Most of the health units reported not having space committed for nutrition activities. This is likely to affect the implementation of IMAM guidelines (2010), which emphasize that emergency nutrition treatment can be given where there is room for a couch, bed or trolley and enough space for staff to examine the clients. Lack of designated space limits capacity and functionality of nutrition activities at health facility level.

According to MoH 2016, physical infrastructure is one of the 9 dimensions of quality of care that must be taken care of when assessing the quality of nutrition care provided through nutrition assessment, counselling, and support (NACS) at health facilities. Physical infrastructure and comfort including the physical appearance of the facility, cleanliness, comfort and privacy are important for clients' experience.

\subsection{IYCN Policy Guidelines and Nutrition IEC Materials}

Capacity based on availability of infant and young child nutrition management policy guidelines was found to be very low (12.7\%) among public health facilities. One of the strategies for strengthening advocacy and social mobilization for behavioral change in nutrition advanced by the HSSP III is developing and disseminating nutrition IEC materials using visual and print media. This strategy remains in balance if IEC materials don't reach the health facilities or are not utilised well.

Similar observations were made by the Fanta (2010) study that was done to analyze the nutrition situation in Uganda. It was observed that Uganda has many good up-to-date technically sound policies and guidelines, but most of the policies and guidelines have been launched in Kampala but not in the regions or districts where they are supposed to operate. The public and donor community has always been concerned about policies and guidelines that have been launched but not available or limited in the regions or districts to guide minimum standards for health service provision. Similar findings are documented by Strides baseline report 2010, policy documents are hardly available in the health facilities in Kamuli district; none of the 11 facilities visited had all the 7 policy guidelines.

The Constitution of the Republic of Uganda requires the state to encourage and promote good nutrition to build a healthy Uganda. It further mandates $\mathrm{MoH}$ and the Ministry of Agriculture, Animal Industry and Fisheries (MAAIF) to set minimum standards and develop relevant policies to ensure provision of quality food and nutrition services in the country. According to Uganda Policy Guidelines on Infant and Young Child Feeding (IYCF, 2009), whether in public or private practice, health care providers are required to be informed of the latest guidelines and tools which help in recognizing malnutrition and LBW and preparedness for IYCF in difficult circumstances, in order to ensure competence in these areas. In response to the need to standardize treatment guidelines, in 2005/2006 and 2010 Uganda updated and disseminated national guidelines for the treatment of moderate and severe acute malnutrition. It is important that IYCN polices/guidelines are made available and health workers oriented and encouraged to use them for quality decisions, plans and actions undertaken to achieve specific malnutrition management goals at health facility level.

\subsection{Planning and Budgeting}

Health facility capacity in terms of planning and budgeting was found to be very low at only $9.7 \%$. The National Nutrition Planning Guidelines for Uganda 2016 observe that nutrition planning is a relatively new process for which little experience exists and since the main aim is to integrate nutrition into overall development plans, it is recommended that the team responsible for nutrition planning start its work early. Effective nutrition 
interventions require joint planning and budgeting with the health sector staff at all levels. Participatory planning and budgeting helps allocation of resources depending on priorities in the district and health facility level.

The budget framework paper FY 2018/19 - FY 2022/23 observes the need for strengthening inter sectoral collaboration to address the social determinants of health e.g. safe water, education, housing, nutrition, etc. this however requires well-coordinated planning and budgeting to utilize the limited budget that is allocated to the health sector. The IMAM guidelines, 2010 recommend joint planning and implementing of emergency nutrition with local authorities and the health sector at all levels, the study revealed limited involvement of health workers in planning and budgeting at facility level. This limits ownership and further affects implementation of agreed actions. By-passing health workers in the planning process reduces the use of valuable health information in decision making and hence low prioritization of the essential nutrition actions at health facility level. The study also indicates that planning for nutrition at health facility level was very low. According to the nutrition bulletin (2008), improvement over the last year in Child Health Days' performance for Vitamin A supplementation and deworming coverage in most areas of the country was as a result of better planning.

The Africa health observatory 2018 observes that the Government of Uganda has steadily increased its budget allocation of funds to the health sector. However, it continues to allocate less than $10 \%$ of its budget to health care, which is less than the 15\% agreed in the Abuja Declaration by heads of African states. The current funding of US\$2 27 per capita per annum expenditure on health care is far below the US\$ 44 per capita recommended. Most donor aid is not harmonized and aligned to the sector plan and managed off-budget and private out-of-pocket expenditure on health is still high. This suggests prioritizing some health services over the others. In fact, one of the health workers said that "nutrition activities are not prioritized because of low resource envelop'. Inadequate planning and budgeting often result in poor implementation of nutrition programmes and projects, duplication of services and programmes without proper equitable distribution and convergence of resources.

\section{Recommendations}

From the results of the study, the following recommendations are advanced to the MoH, Kamuli district health department and health facility managers to enhance public health units' capacity to manage under-five malnutrition.

1. There is need to strengthen nutrition human resources by recruiting nutritionists at health units or appointing nutrition focal persons. Further still through a capacity building plan, conducting in-service training for health workers directly engaged in the management of under-five malnutrition should be planned and implemented. This might go a long way to bridge the gap created by lack of specialized Nutritionist in the Units.

2. Health worker supervisors need to be enhanced with knowledge and skills for support supervision, mentoring and coaching for nutrition. Therefore, the need for a deliberate support supervision plan that follows the systems approach from the MoH, DHT and Health sub district.

3. The DHT should implement a participatory planning, review and budgeting process at health facilities to adequately assess and forecast their resource needs for nutrition. This will further ensure the inclusiveness of Nutrition specific activities and actions in the budgets.

4. Development of an advocacy plan designed to raise the profile of nutrition among the senior district members, the private sector, the media and the donor community. The advocacy plan should aim to mobilize and raise additional resources for nutrition programming in the district and health facilities. The plan should further focus on human resources, capacity building and linkages to the HSSP deliverables including the burden of under-five Malnutrition.

5. Motivation of health workers to provide quality nutrition services for under-five year children e.g. praise and recognition, generous benefits, vacation time, access to internet services and access to training opportunities. In this regard the $\mathrm{MoH}$ needs to target increasing resources for nutrition supplies especially therapeutic foods and anthropometric equipment as lack of adequate consumables for management of malnutrition is the biggest contributor to poor service delivery.

\section{Conclusion}

The study indicates overall limited capacity $(36.4 \%$.) of public health facilities to manage under-five malnutrition in Kamuli district. This is associate with; health units operating with a workforce below recommended staff establishment and lack of nutritionists and or nutrition focal persons. Health facilities were also challenged by inadequate availability of therapeutic foods, and limited health workers' knowledge for 
identification, screening and treatment of under-five children with malnutrition. In addition, planning and budgeting for health that is not inclusive, weak monitoring, reporting and supervision system were also identified as responsible for limited capacity of health facilities to manage under-five malnutrition. It is also important to note that health workers are aware of barriers and solutions for adequate management of under-five malnutrition.

\section{Special Acknowledgement}

In a special way I acknowledge Professor Gail Nonneck, her husband Brian, Son Eric Nonneck and Dr. Dorothy Masinde for the financial support, professional guidance and encouragement through my graduate study and research. I acknowledge my beloved daughters Michelle Deborah Kirabo and Hannah Alexis Tusubira for the patience while I was doing this work. I appreciate the school of public health, my supervisors Dr. Elizabeth Kiracho Ekirapa and Mr Saul Kamukama for the professional guidance, and associate Professor Peter Waiswa who oversaw the final improvements of my research. I would like to thank all public health workers in Kamuli district for giving me the opportunity and support to conduct this research. Their excitement and willingness to participate in the study made the completion of this research an enjoyable experience.

\section{References}

Beatrice, O. et al. (2011, August). Nutritional Status of Under-five Children Living in an Informal Urban Settlement in Nairobi, Kenya. Journal of Health population and Nutrition, 29(4), 357-363. https://doi.org/10.3329/jhpn.v29i4.8451

Bruno, F., \& Sunguya, K.C. et al. (2013). Nutrition Training Improves Health Workers' Nutrition Knowledge and Competence to Manage Child Undernutrition. Retrieved from https://www.ncbi.nlm.nih.gov/pmc/articles/PMC3859930/

Businge, D., Smith, M.O., Kironde, S., \& Begumisa, A. (2010). STAR-EC LQAS Survey Report 2011: A health facility assessment and household LQAS survey on HIV\&AIDS and TB interventions in nine districts in East Central Uganda. STRIDES for Family Health, 2010: Kamuli district baseline/ needs assessment report. Retrieved from http://4c4is7252hqpkrpks2aw15j1.wpengine.netdna-cdn.com/wp-content/uploads/2016/08/STAR-EC-LQA S_Final_Report_2011.pdf

Edgar, A. (2009, October). Funding the promise; monitoring Uganda's health sector financing from an HIV/AIDS perspective. African Health Sciences, 9 (Suppl 2), S81-S85. https://www.ncbi.nlm.nih.gov/pmc/articles/PMC2877291/

FANTA-2. (2010). The Analysis of the Nutrition Situation in Uganda. Food and Nutrition Technical Assistance II Project (FANTA-2). FHI 360. 1825 Connecticut Ave., NW Washington, DC 20009-5721. Retrieved from https://www.fantaproject.org/sites/default/files/resources/Uganda_NSA_May2010.pdf

Global nutrition report. (2016). Retrieved from http://globalnutritionreport.org/the-report-2016/

Government of Uganda. (2010). Human Resources for Health Audit Report 2010. Ministry of Health. Human Resource Management. Retrieved from http://library.health.go.ug/publications/health-workforce/human-resource-management/human-resources-he alth-audit-report-2010

Government of Uganda. (2010). integrated management of acute malnutrition guidelines. Ministry of Health, $\begin{array}{llll}\text { Uganda } & \text { (IMAM } & \text { 2010). } & \text { Retrieved }\end{array}$ https://www.medbox.org/countries/uganda-integrated-management-of-acute-malnutrition-guidelines/previe w?q

Government of Uganda. (2010). Ministry of Health 2010/11-2014/15. The Uganda health sector strategic and investment plan. Retrieved from http://library.health.go.ug/publications/leadership-and-governance-governance/policy-documents/health-sec tor-strategic-and

Government of Uganda. (2010). Ministry of Health, 2010/11-2014/15 (pp. 11-12). Health sector strategic plan III (HSSP III), Uganda. Retrieved from http://www.health.go.ug/docs/HSSP_III_2010.pdf

Government of Uganda. (2010). The Uganda Nutrition Action Plan, 2010-2015 (p. 25). Scaling up Multi-Sectoral Efforts to Establish a Strong Nutrition Foundation for Uganda's Development. Ministry of Health. Retrieved from https://www.fantaproject.org/sites/default/files/resources/Uganda_NutritionActionPlan_Nov2011.pdf 
Kamuli District Local Government. (2009). Higher local government statistical abstract, Kamuli district. Retrieved from http://www.ubos.org/onlinefiles/uploads/ubos/2009_HLG_\%20Abstract_printed/kamuli\%20district\%20ann ual\%20abstract.pdf

Kate, S. et al. (2011). Community Case Management of Severe Acute Malnutrition in Southern Bangladesh. Strengthening the humanity and dignity of people in crisis through knowledge and practice. Retrieved from http://sites.tufts.edu/feinstein/program/community-based-management-of-severe-acute-malnutrition-in-bang ladesh

MoH. (2016). Integrating Nutrition Assessment, Counselling, and Support into Health Service Delivery. Retrieved from https://www.fantaproject.org/sites/default/files/resources/Uganda-NACS-Reference-Manual-June2016_0.pd $\mathrm{f}$

National Nutrition Planning Guidelines for Uganda. (2016). Retrieved from $\mathrm{http} / / / \mathrm{npa} . u g / \mathrm{wp}-$ content/uploads/nutrition-planning-guidelines.pdf

Nutrition, B. (2008). Wiley Online Library. British Nutrition foundation, 33(4), 269-271. Retrieved from https://onlinelibrary.wiley.com/toc/14673010/33/4

Peter, R. (2010). Fanta2 Health and Nutrition brief 1. Secretary General, Uganda Action for Nutrition Society $(U G A N)$, Department of Food Science and Technology. P.O BOX 7062, Kampala, Uganda. Retrieved from https://www.fantaproject.org/sites/default/files/resources/Uganda_Health\%20and\%20Nutrition_Dec2010.p df

Potter, C., \& Brough, R. (2004). Systemic capacity building: a hierarchy of needs. Retrieved from https://pdfs.semanticscholar.org/ea49/208b4878435c3ae3dd3451e0fd7de4a165b1.pdf

Steve, C. (2007, May). Treating severe acute malnutrition seriously. Archives of Disease in children, 92(5), 453-461. https://doi.org/10.1136/adc.2006.098327

The budget framework paper FY 2018/19-FY 2022/23. (2018). Retrieved from http://ugandajournalistsresourcecentre.com/uganda-health-sector-budget-framework-paper-fy-201819-fy-20 $2223 /$

The health workforce crisis in Bangladesh: shortage, inappropriate skill-mix and inequitable distribution. (2011). Human Resources for Health, 9, 3. Retrieved from https://human-resources-health.biomedcentral.com/articles/10.1186/1478-4491-9-3

Uganda demographic health survey. (2016). Retrieved from https://www.ubos.org/onlinefiles/uploads/ubos/pdf\%20documents/Uganda_DHS_2016_KIR.pdf

World Bank-Child $\quad$ Malnutrition. $\quad$ (2018). Retrieved from https://blogs.worldbank.org/category/tags/child-malnutrition

World Health Organisation. (2014). WHO Global Health Expenditure Atlas. 1. Health expenditures-statistics and numerical data. 2. Health systems plans. 3. Universal coverage. 4. National health programs. 5. Atlases. I. World Health Organization. ISBN 9789241504447 (NLM classification: W 74). Retrieved from http://www.who.int/health-accounts/atlas2014.pdf

Zultique, A. et al. (2010). Global Experience of Community Health Workers for Delivery of Health Related Millennium Development Goals. A Systematic Review, Country Case Studies, and Recommendations for Integration into National Health Systems. WHO, Global Evidence of Community Health Workers. Retrieved from http://www.who.int/workforcealliance/knowledge/publications/alliance/Global_CHW_web.pdf

\section{Copyrights}

Copyright for this article is retained by the author(s), with first publication rights granted to the journal.

This is an open-access article distributed under the terms and conditions of the Creative Commons Attribution license (http://creativecommons.org/licenses/by/4.0/). 